\title{
Complementarity of radioautographic and immunohistochemical techniques for localizing neuroreceptors at the light and electron microscopy level
}

\section{A. Beaudet, \\ P. Dournaud and $\mathrm{H}$. Boudin}

Montreal Neurological Institute, McGill University, Montreal, Quebec, Canada

\section{Correspondence \\ A. Beaudet \\ Montreal Neurological Institute 3801 University Street \\ Montreal, Quebec H3A 2B4 \\ Canada}

Presented at the 5th International Symposium on Radioautography, São Paulo, SP, Brasil,

August 24-26, 1997.

The present address of $P$. Dournaud is INSERM U.159, 2ter, rue d'Alésia 75014 Paris, France.

Received November 19, 1997 Accepted November 24, 1997

\section{Abstract}

To assess relationships between neuropeptide-binding sites and receptor proteins in rat brain, the distribution of radioautographically labeled somatostatin and neurotensin-binding sites was compared to that of immunolabeled sst2A and NTRH receptor subtypes, respectively. By light microscopy, immunoreactive sst2A receptors were either confined to neuronal perikarya and dendrites or diffusely distributed in tissue. By electron microscopy, areas expressing somatodendritic sst2A receptors displayed only low proportions of membrane-associated, as compared to intracellular, receptors. Conversely, regions displaying diffuse sst $2 \mathrm{~A}$ labeling exhibited higher proportions of membrane-associated than intracellular receptors. Furthermore, the former showed only low levels of radioautographically labeled somatostatin-binding sites whereas the latter contained high densities of somatostatin-binding suggesting that membrane-associated receptors are preferentially recognized by the radioligand. In the case of NTRH receptors, there was a close correspondence between the light microscopic distribution of NTRH immunoreactivity and that of labeled neurotensin-binding sites. Within the substantia nigra, the bulk of immuno- and autoradiographically labeled receptors were associated with the cell bodies and dendrites of presumptive DA neurons. By electron microscopy, both markers were detected inside as well as on the surface of labeled neurons. At the level of the plasma membrane, their distribution was highly correlated and characterized by a lack of enrichment at the level of synaptic junctions and by a homogeneous distribution along the remaining neuronal surface, in conformity with the hypothesis of an extra-synaptic action of this neuropeptide. Inside labeled dendrites, there was a proportionally higher content of immunoreactive than radiolabeled receptors. Some of the immunolabeled receptors not recognized by the radioligand were found in endosomelike organelles suggesting that, as in the case of sst $2 \mathrm{~A}$ receptors, they may have undergone endocytosis subsequent to binding to the endogenous peptide.
Key words

- Neurotensin

- Somatostatin

- Internalization

- Neuropeptides

- Autoradiography

- Ultrastructure 


\section{Introduction}

For more than twenty years, radioautography has been the method of choice for visualizing neurotransmitter receptors or, more specifically, neurotransmitter-binding sites in mammalian brain. Original labeling methods relied on in vivo administration of radioligands by the parenteral (1) or intracerebroventricular (2) route followed by radioautographic processing of frozen brain sections using dry radioautographic techniques (3). Young and Kuhar (4) were later to devise an in vitro radioligand-binding technique which, combined with the use of dry emulsion-covered coverslips (4) or tritium sensitive film (5), was to be universally applied to the study of the regional distribution of a variety of neurotransmitter receptors in the central nervous system (CNS). The introduction of photoaffinity probes and of radioligands that lent themselves to crosslinking by divalent agents made it possible to visualize covalently labeled receptors by means of standard wet autoradiographic techniques $(6,7)$. This technical improvement significantly increased the resolution of receptor detection allowing their visualization at both the cellular (e.g., 8-11) and subcellular levels $(7,12-15)$.

During the last decade, the cloning of a multiplicity of neuroreceptor subtypes as well as of various subunits of ligand-gated channels made it possible to visualize neurotransmitter receptors in the brain by immunohistochemistry through the development of antibodies directed against specific amino acid sequences of the cloned proteins. This approach has the advantage of permitting the selective detection of molecularly defined receptor subtypes. It also affords a considerably higher resolution than radioautography, particularly when conjugated to immunogold detection systems. This increased resolution permits better differentiation between somatodendritic (e.g., post-synaptic) and axonal (i.e., pre-synaptic) receptors than was previ- ously possible with radioautography at the light microscopic level, even using high resolution dipping techniques. At the electron microscopy level, it permits the determination of both the nature of the receptor-bearing element (neuronal or glial; dendritic versus axonal) and the identity of the subcellular organelles with which the receptors are associated.

These advantages of immunohistochemical over radioautographic localization techniques have led many to believe that radioautography was no longer a method of choice for studying the distribution of neuroreceptors in the brain. However, this is clearly not the case since radioautography i) remains a viable approach for visualizing receptors that have not yet been cloned, ii) is a method of choice for the recognition of functional receptors (i.e., capable of ligand binding), and iii) is an approach which readily lends itself to the study of the pharmacological properties of neurotransmitter-binding sites as well as to the visualization of the sites of action of a variety of centrally acting drugs.

In our own work, we have taken advantage of the complementarity of radioautographic and immunohistochemical techniques to gain insight into the functional significance of the cellular and subcellular distribution of neuropeptide receptors in the CNS. The examples that follow are taken from recent studies from our laboratory on the light and electron microscopy distribution of somatostatin and neurotensin receptors in the rat brain.

\section{Light and electron microscopy localization of somatostatin sst2A receptors in rat brain}

In a first set of studies (16), we compared the immunohistochemical distribution of sst $2 \mathrm{~A}$ somatostatin receptors (one of the six somatostatin receptor subtypes cloned to date) with the radioautographic distribution of sst2-binding sites in serial sections of the 
rat brain. sst $2 \mathrm{~A}$ receptors were labeled using tyramide-amplified peroxidase (light microscopy) or immunogold (electron microscopy) techniques with an antibody directed against a specific amino acid sequence located in the C-terminus of the receptor, developed and characterized by Dr. Agnes Schonbrunn, Houston, TX. sst2-binding sites were labeled in vitro by incubation of frozen sections with an iodinated somatostatin analogue ( ${ }^{125}$ I-D-Trp8-somatostatin), as described by Dournaud et al. (17). Immunohistochemical results were also compared to radioautographic data generated with sst2preferring radioligands, as reported in the literature (reviewed in 16).

At low light microscope magnification, sst2A-immunoreacted sections exhibited selective and intense sst $2 \mathrm{~A}$ receptor labeling in a number of brain areas, and most conspicuously in deep layers of cerebral cortex, CA1 and CA2 subfields of the hippocampus, medial habenula, bed nucleus of the stria terminalis, endopiriform nucleus, claustrum and amygdaloid complex. Dense sst2A immunoreactivity was also observed within several brainstem nuclei, including the locus coeruleus, pontine nuclei, and nucleus trac- tus solitarius (18).

At higher light microscope magnification, sst2A immunolabeling was either confined to neuronal perikarya and dendrites or diffusely distributed in tissue. Comparison of this labeling pattern with that of sst2binding sites labeled by radioautography, using either ${ }^{125}$ I-D-Trp8-somatostatin or sst2preferring ligands, revealed that in regions in which sst $2 \mathrm{~A}$ immunoreactivity was present over nerve cell bodies and dendrites concentrations of radiolabeled somatostatin-binding sites were highly variable, ranging from high in regions such as the medial habenula to very low in regions such as the upper layers of the cerebral cortex (Figure 1b,c) or the central nucleus of the amygdala. Quantitative analysis confirmed the total lack of correlation between the distribution of sst $2 \mathrm{~A}$ somatodendritic immunolabeling and that of somatostatin-binding sites radioautographically labeled using sst2-preferring ligands ( $\mathrm{r}$ $=0.24 ; \mathrm{P}<0.3)$. By contrast, in areas in which it appeared diffusely distributed in tissue (e.g., in deep layers of the cerebral cortex, Figure 1b), sst2A immunolabeling showed a striking correspondence with the distribution pattern of radioautographically labeled
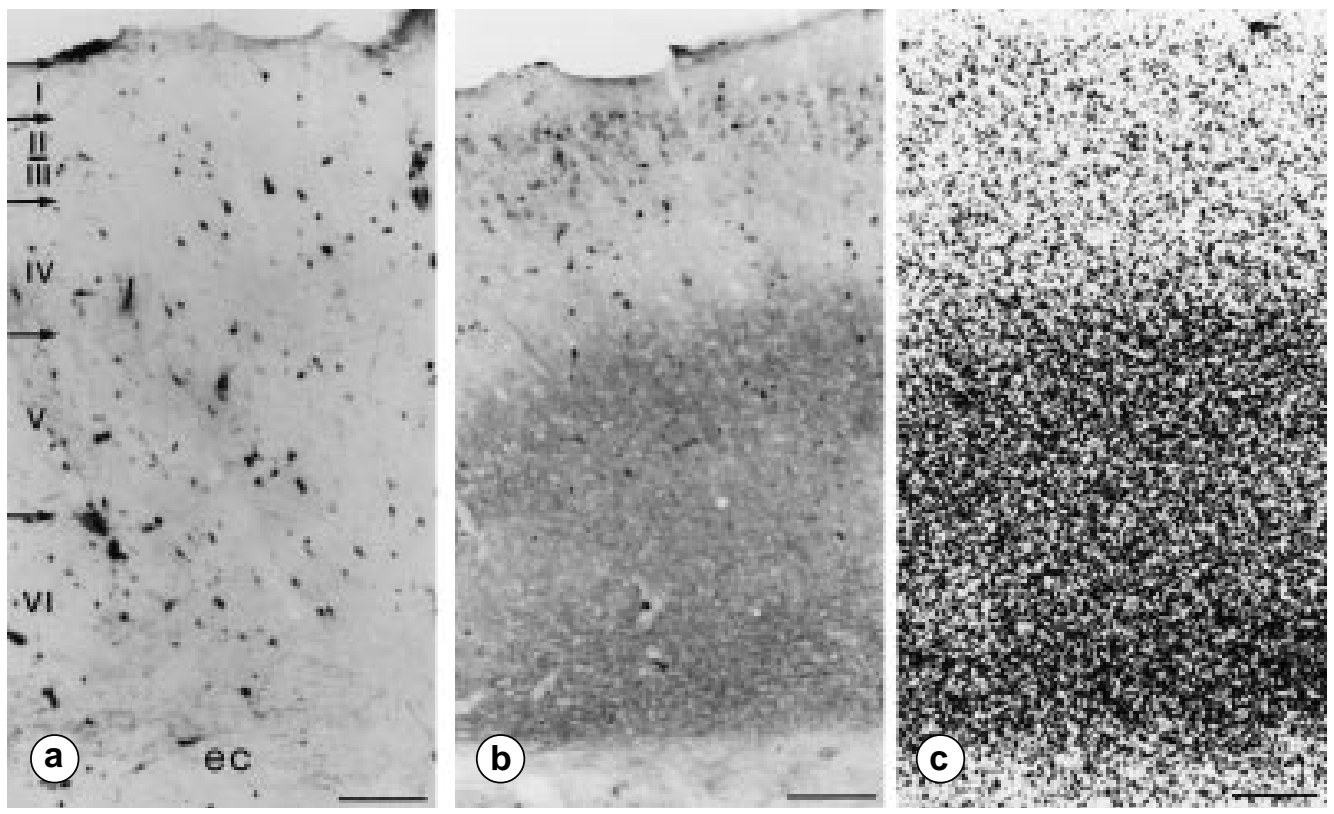

Figure 1 - Comparative distribution of somatostatin immunoreactivity (a), sst2A receptor immunoreactivity (b) and autoradiographically labeled somatostatin-binding sites (c) in the parietal cortex. a, Numerous somatostatin immunoreactive nerve cell bodies are distributed throughout layer II to layer VI. $b$, Numerous sst2A receptor-expressing neurons are evident in layers II-III, whereas diffuse sst2A labeling pervades the outer part of layer $\mathrm{V}$ and the deeper part of layer VI. c, The distribution pattern of 125/-DTrp8-somatostatin-binding sites is superimposable over that of sst2A diffuse labeling in layers V-VI. ec: External capsule. Scale bars: $45 \mu \mathrm{m}$. 
sst2-binding sites (Figure 1b,c). Furthermore, a high correlation was observed between the density of diffuse sst2A immunolabeling and that of radioautographically labeled sst2Abinding sites (Figure 2; $\mathrm{r}=0.94 ; \mathrm{P}<0.0001$ ).

An inverse relationship was observed when the distribution of sst2A-immunoreactive receptors was compared to that of somatostatin axon terminals immunohistochemically detected in the same or adjacent sections using a specific antibody directed against somatostatin (16). Specifically, there was a strong correlation between sst $2 \mathrm{~A}$ immunolabeling and somatostatin terminal densities in regions in which sst2A immunolabeling was clearly somatodendritic (e.g., in the central nucleus of the amygdala). By contrast, in regions exhibiting diffuse sst $2 \mathrm{~A}$ immunolabeling (and dense radioautographic labeling of somatostatin-binding sites), somatostatin-immunoreactive axons were only sparse (e.g., in deep layers of cerebral cortex, Figure 1a-c).

In order to investigate the reason for these discrepancies, we compared the fine structural distribution of sst2A-immunoreactive receptors in regions of somatodendritic and of diffuse sst2A labeling using immunogold cytochemistry. As can be seen in Figure 3, in regions of selective somatodendritic sst $2 \mathrm{~A}$ immunolabeling, immunolabeled receptors were found by electron microscopy to be

Figure 2 - Correlation between the density of membrane-associated immunoreactive sst2A receptors and that of somatostatin-binding sites documented by quantitative autoradiography using sst2-preferring ligands. Using Spearman's coefficient, a highly significant correlation is found between immunological and autoradiographic signals $(r=$ 0.94, $\mathrm{P}<0.0001)$. Endo. n., Endopiriform nucleus; NTS, nucleus tractus solitarius; CG, central gray; SI, substantia innominata; $\mathrm{SN}$, substantia nigra; $\mathrm{ZI}$, zona incerta.

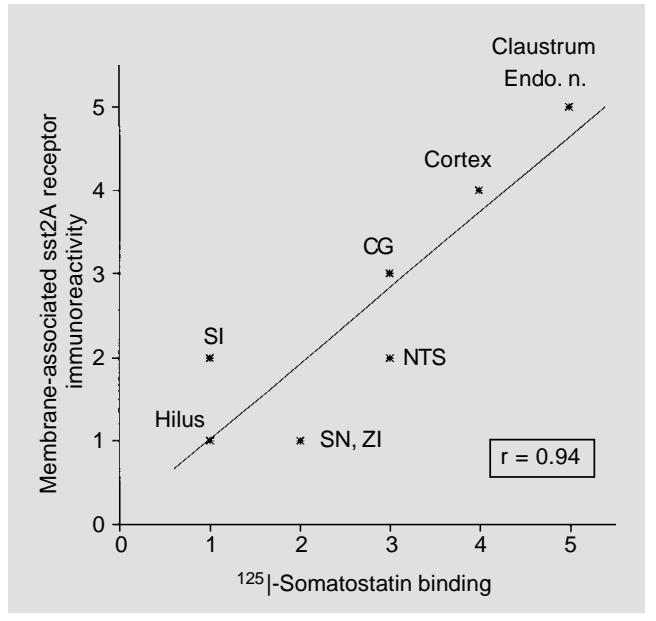

mainly concentrated inside neuronal perikarya and dendrites rather than associated with their plasma membrane. In fact, quantitative analysis demonstrated that over $78 \%$ of labeled receptors were intracellular whereas only $22 \%$ were membrane bound. Inside labeled neurons, immunoreactive receptors were evident over structures involved in protein synthesis and glycosylation (i.e., endoplasmic reticulum and Golgi apparatus) as well as over vesiculotubular organelles characteristic of endosomal compartments (Figure 3a).

In contrast, in areas in which immunolabeled sst $2 \mathrm{~A}$ receptors appeared diffusely distributed by light microscopy, electron microscopy revealed a predominant association of the label with neuronal plasma membranes $(70 \%)$ as opposed to the interior of the cells (30\%). As can be seen in Figure 3b, membrane-associated receptors were haphazardly distributed along the plasma membrane without obvious concentration over sites of synaptic specialization or opposite abutting axon terminals.

These results indicate that membranebound sst $2 \mathrm{~A}$ receptors preferentially recognize radiolabeled ligands. In contrast, intracellular receptors recognize radioactive somatostatin analogs poorly, presumably because of a different molecular conformation and/or functional state. What is particularly intriguing here is the finding that regions in which sst2A somatostatin receptors are predominantly intracellular are the ones that receive a dense somatostatin innervation, whereas in regions in which sst $2 \mathrm{~A}$ receptors are predominantly membrane bound, somatostatin axon terminals are only sparse. One possible interpretation for these findings is that in regions of dense somatostatin innervation, membrane-associated sst2A receptors are chronically down-regulated because of a massive release of endogenous somatostatin. Such a down-regulation would obviously be much less pronounced in regions of sparse somatostatin innervation, hence 
the large proportion of membrane-associated receptors found in these areas. The frequency at which intracellular receptors were found in association with endosomelike organelles suggests that this downregulation may be predicated on somatostatin-induced internalization of receptorligand complexes. Such an interpretation is consistent with the earlier demonstration that the sst $2 \mathrm{~A}$ receptor subtype may undergo ligand-induced internalization in transfected cells as well as in natural cell lines (19-21).

\section{Comparative distribution of high-affinity neurotensin receptors and specific neurotensin-binding sites in rat substantia nigra}

In a separate set of experiments (Boudin H, Pélaprat D, Rostène W, Pickel VM and Beaudet A, unpublished results), we compared the light and electron microscopy distribution of immunocytochemically labeled neurotensin receptor proteins with that of radioautographically labeled high-affinity neurotensin-binding sites. In contrast to somatostatin, only two receptors for the tridecapeptide neurotensin have been cloned to date: a high-affinity site $(\mathrm{Kd}=0.1 \mathrm{nM})$ expressed in restricted areas of the rodent brain $(9,22,23)$ and a low-affinity site $(\mathrm{Kd}=$ $1 \mu \mathrm{M})$ the expression of which is considerably more widespread (24; Sarret P, Beaudet A, Vincent JP and Mazella J, unpublished results). Of these two receptors, the highaffinity receptor (NTRH) is the one that appears to be involved in most of the documented effects of neurotensin. In particular, it has been shown to be responsible for the potent excitatory effects of neurotensin on mesencephalic dopaminergic cells (25-27). This finding is consistent with the high concentration of NTRH detected in association with dopaminergic cells in the substantia nigra and adjacent ventral tegmental area (28-30).
NTRH receptor proteins were immunolabeled using either tyramide-amplified peroxidase (light microscopy) or immunogold (electron microscopy) techniques with a specific antibody directed against an amino acid sequence of the third intracellular loop of the receptor. This antibody was developed and characterized in Dr. William Rostène's laboratory in Paris $(23,31)$. High-affinity neurotensin-binding sites were detected in sections of the rat brain labeled in vitro, using concentrations of iodinated neurotensin $(0.1$ $\mathrm{nM}$ ) that ensure selective labeling of the high-affinity neurotensin receptor subtype (for a detailed description of the methodology for radioautographic labeling of NTRH at light and electron microscopic levels, see references 9,14).

At the light microscopy level, there was a close correlation between the topographic distributions of immunolabeled and radioautographically labeled NTRH receptors. This is illustrated in Figure 4 for two areas of particularly dense NTRH enrichment: the substantia nigra and suprachiasmatic nucleus of the hypothalamus. As previously reported $(23,30,32)$, in both of these areas neuro-

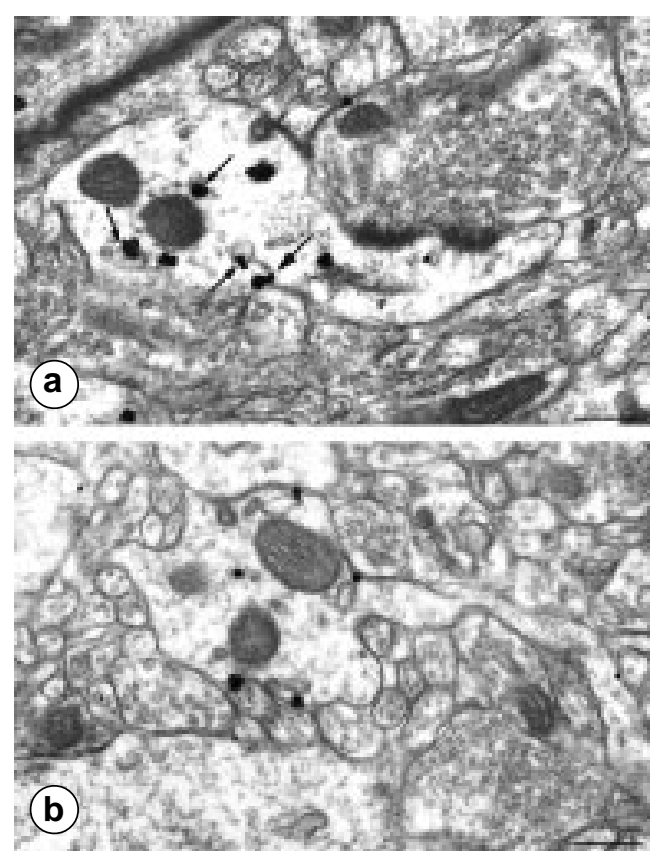

Figure 3 - Electron microscopy localization of sst2A receptors using silver-enhanced immunogold in the bed nucleus of the stria terminalis (a) and claustrum (b). a, Immunolabeled receptors are detected inside a large dendritic shaft. Note the frequent association of gold particles with endosome-like organelles (small arrows). Only one of the gold particles is associated with the plasma membrane (large arrow). $b$, Gold particles are predominantly associated with the plasma membrane of a dendrite. Note the lack of receptor enrichment opposite abutting axon terminals. Scale bars: $0.3 \mu \mathrm{m}$. 
Figure 4 - Comparative light microscopy distribution of NTRH immunoreactivity (left) and ${ }^{125}$ NT-binding sites (right) in the substantia nigra and ventral tegmental area $\left(\mathrm{a}, \mathrm{a}^{\prime}\right)$ and in the suprachiasmatic nucleus (b,b'). In both regions, the distribution of immunostaining matches that of autoradiographic labeling. $a, a^{\prime}$, The labeling is prominent in the substantia nigra, pars compacta (SNC) and in the ventral tegmental area (VTA) where it is predominantly associated with nerve cell bodies and dendrites. The dendritic meshwork is especially dense in the SNC wherefrom it extends into the substantia nigra, pars reticulata (SNR). $b, b$, The labeling is concentrated in the ventral part of the suprachiasmatic nucleus (SCh) in which it also predominates over somatodendritic elements. III, Third ventricle; ox, optic chiasm. Scale bars: $300 \mu \mathrm{m}$
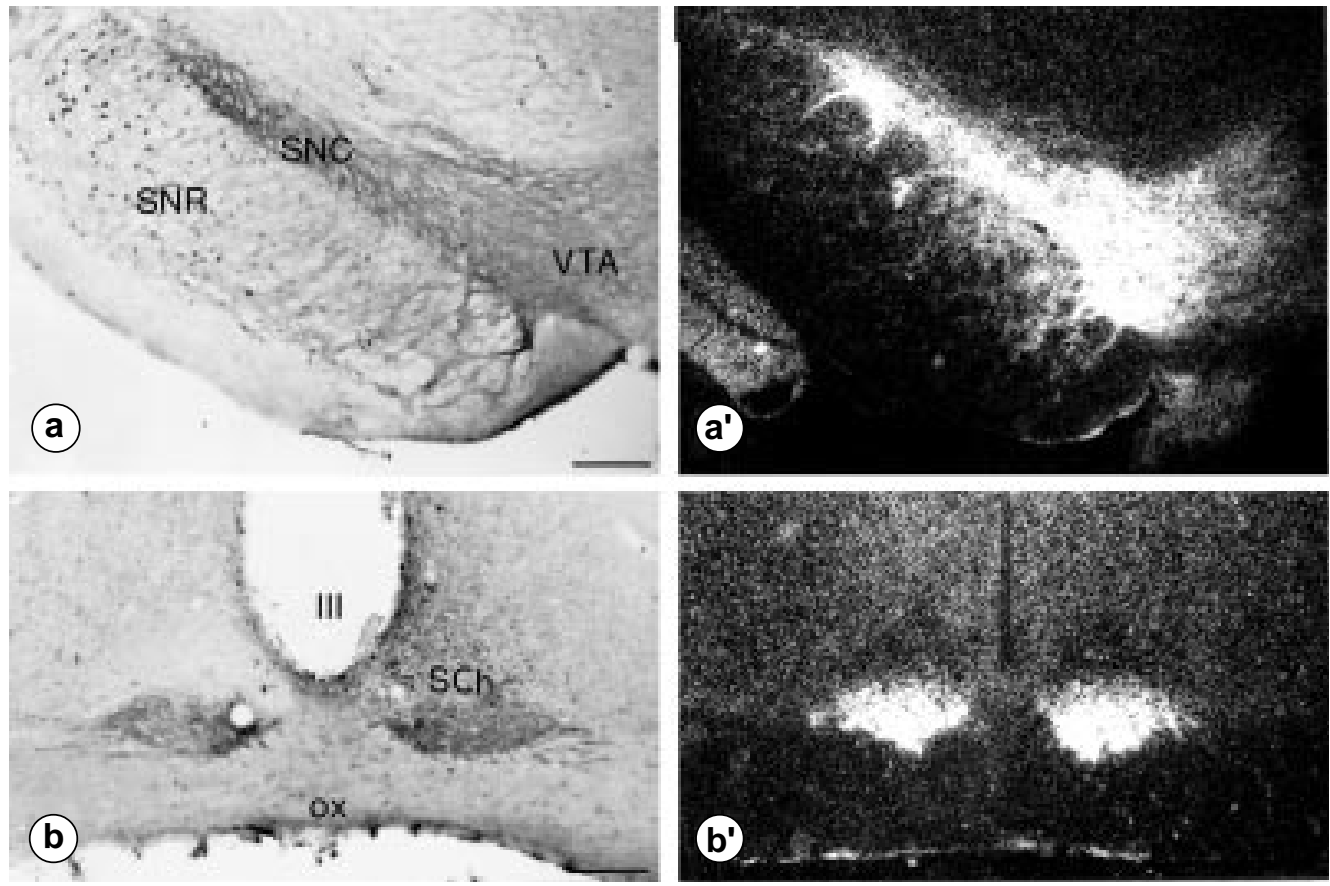

tensin immunoreactive receptor proteins were mainly associated with neuronal perikarya and dendrites (Figure 4).

Electron microscopy examination of the rat substantia nigra confirmed the overall similarity between the fine structural distributions of radioautographically and immunolabeled NTRH receptors. Thus, as predicted from light microscopy results (see Figure 4), both markers were almost exclusively associated with neuronal perikarya and dendrites which, on the basis of earlier double-labeling (30) and lesion studies (28), may be surmised to be mainly dopaminergic. However, quantitative analyses of immunogold and radioautographic silver grain distribution (for a description of the methodology for statistical analysis of radioautographs, see reference 33 ) revealed subtle differences between the distributions of the two markers. Thus, whereas in electron microscopy radioautographs a slightly larger proportion of labeled-binding sites was associated with plasma membranes $(55 \%)$ than with intracellular compartments (45\%), in immunoreacted sections intracellular receptors were proportionally more numerous than plasma

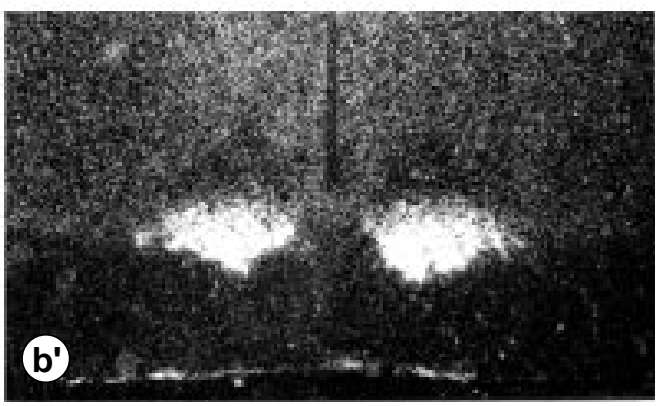

membrane-associated ones ( $73 \%$ vs $27 \%)$.

In spite of these quantitative differences, both markers showed a remarkably similar distribution along the length of neuronal plasma membranes (Figures 5 and 6). A striking feature of this distribution was the lack of receptor enrichment at the level of synaptic junctions. Rather, both markers were more or less evenly distributed along somatodendritic plasma membranes with no apparent predilection for any of the opposite abutting elements. Such a homogeneous distribution is consistent with the earlier demonstration that, within the substantia nigra, neurotensin-containing axon terminals only rarely contact neurotensin receptor-bearing (i.e., dopaminergic) cells (34). It is also congruent with the previously proposed hypothesis that throughout several regions of the brain, including the substantia nigra (34), ventral tegmental area (14) and basal forebrain (35), neurotensin acts in a parasynaptic manner by diffusion for short distances into the extracellular space.

Inside nerve cell bodies, both NTRH receptor proteins and binding sites were evident over the endoplasmic reticulum and 
Golgi apparatus, suggesting that newly synthesized NTRH receptors already possess the molecular conformation necessary for recognition of the ligand. At the level of labeled dendrites, however, there were marked discrepancies between the intracellular distributions of radioautographic and immunocytochemical markers. First, immunoreactive NTRH receptor proteins were relatively more abundant than radiolabeled neurotensin-binding sites, which probably accounts for the larger proportion of intracellular receptors found in immunocytochemical preparations. Second, a higher proportion of immunogold particles than of radioautographic silver grains was found in association with vesicular and/or tubulovesicular endosome-like elements. Our interpretation for these discrepancies is that, as in the case of sst2A receptors, a proportion of intradendritic NTRH receptor proteins is either unrecognized by or unaccessible to the radioligand. This unaccessibility may be due to the trapping of the receptors in endosomes subsequent to their agonist-induced internalization into target cells. This interpretation is supported by the earlier demonstration of receptor-mediated internalization of fluorescent neurotensin in nigrostriatal neurons (36) as well as by the demonstration that this internalization is mediated by the high-affinity neurotensin receptor subtype (37).

\section{Conclusions}

In summary, the present data illustrate the complementarity of radioautographic and immunohistochemical techniques for localizing and assessing the functionality of neuropeptide receptors in the CNS at the light and electron microscopy levels. The correlative data obtained here by conjugating these two techniques for visualizing sst2A somatostatin and NTRH neurotensin receptors in the rat brain have made it possible to draw the following conclusions: 1) whereas im-

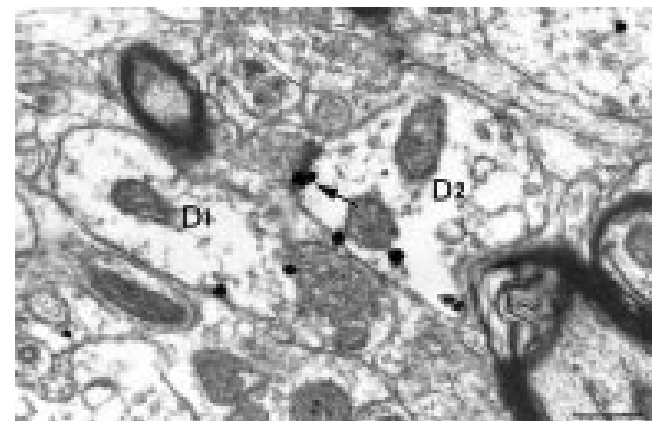

Figure 5 - Electron microscopy localization of immunogold-labeled NTRH receptors in the rat substantia nigra, pars compacta. Gold particles are detected along the plasma membranes of two adjacent dendritic profiles (D1 and D2). Note the presence of a labeled receptor at the level of an asymmetrical synaptic junction (arrow). Scale bar: $0.5 \mu \mathrm{m}$.

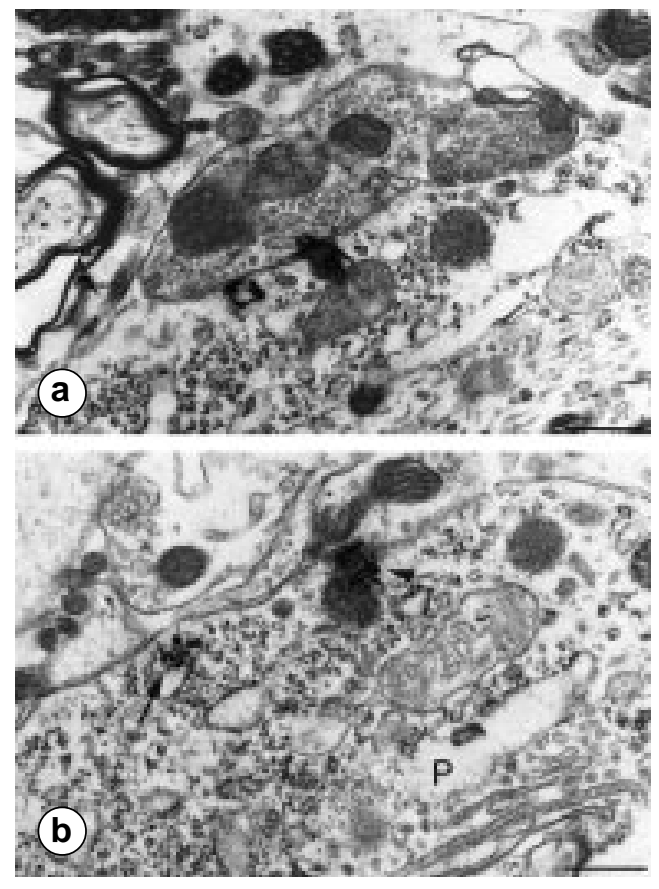

munocytochemical markers recognize both intracellular and membrane-associated forms of the receptors, radiolabeled ligands may or may not recognize intracellular receptors depending on the accessibility and/or molecular conformation of the latter. These results imply that radioautography, even when carried out after in vitro labeling, may be a better predictor of the sites of action of exogenously administered than of endogenously released neuropeptides. 2) At the level of neuronal plasma membranes, our studies showed a remarkable concordance between the distribution of neuropeptide receptor proteins and that of specific transmitter-binding
Figure 6 - Electron microscopy detection of radioautographically labeled 125 I-NT-binding sites in the rat substantia nigra. a) Two radioautographic silver grains are detected over an axosomatic apposition. The abutting axon terminal contains densely packed clear synaptic vesicles. $b$, Two silver grains are associated with the plasma membrane of a neuronal perikaryon $(\mathrm{P})$. One of the silver grains is detected opposite an astroglial sheath (arrow) and the other at the level of an incoming axon terminal containing only sparse clear synaptic vesicles (arrowhead). Scale bars: $0.6 \mu \mathrm{m}$. 
sites. Both markers were found to be uniformly distributed along the membranes, with no evidence of enrichment at the level of synaptic specializations. These results suggest that receptor proteins present on the surface of the neurons, and not only those found opposite abutting axon terminals or at the level of synaptic junctions, are functional (i.e., are in a conformation that recognizes endogenous as well as exogenous ligands). This proposal is consistent with the parasynaptic mode of neurotransmission previously proposed for a number of neuropeptides in the CNS. 3) Our results suggest that a proportion of intracellular receptors do not recognize radioactive ligands because they are trapped in endosome-like compartments. This interpretation implies that cell surface receptors may undergo down-regulation upon agonist-induced internalization into their target cells. This interpretation is in keeping with the recent proposal that there might be widespread receptor-mediated internalization of neuropeptides through receptor-mediated mechanisms in the CNS (e.g., 38-40). Internalization is a process that has been linked to a variety of functions, including ligand sequestration and degradation (41), receptor desensitization/resensitization and recycling (42) and intracellular neuropeptide signalling (43). The extent of this internalization, however, appears to vary from one receptor to another and may be related in part to the density of innervation of receptor-bearing cells by axon terminals that store and release the receptor's endogenous ligand.

\section{References}

1. Pert CB, Kuhar MJ \& Snyder SH (1976). Opiate receptor: autoradiographic localization in rat brain. Proceedings of the National Academy of Sciences, USA, 73: 3729-3733.

2. Hunt SP \& Schmidt J (1978). The electron microscopic autoradiographic localization of $\alpha$-bungarotoxin-binding sites within the central nervous system of the rat. Brain Research, 142: 152-159.

3. Stumpf WE \& Roth LG (1966). High resolution autoradiography with dry mounted freeze-dried frozen sections. Comparative study of six methods using two diffusable compounds ${ }^{3} \mathrm{H}$-estradiol and ${ }^{3} \mathrm{H}$-mesobilirubinogen. Journal of Histochemistry and Cytochemistry, 14: 274-287.

4. Young WS \& Kuhar MJ (1979). A new method for receptor autoradiography: ${ }^{3} \mathrm{H}$ opioid receptor labeling in mounted tissue sections. Brain Research, 179: 255-270.

5. Palacios JM, Niehoff DL \& Kuhar MJ (1981). Receptor autoradiography with tritium-sensitive film: Potential for computerized densitometry. Neuroscience Letters, 24: 111-116.

6. Hamel E \& Beaudet A (1984). Localization of opioid-binding sites in rat brain by electron microscopic radioautography. Journal of Electron Microscopy Technique, 1: 317329.
7. Pasquini $F$, Bochet $P$, GarbayJaureguiberry C, Roques BP, Rossier J \& Beaudet A (1992). Electron microscopic localization of photoaffinity-labelled delta opiod receptors in the neostriatum of the rat. Journal of Comparative Neurology 326: 229-244.

8. Herkenham M \& Pert CB (1982). Light microscopic localization of brain opiate receptors: a general autoradiographic method which preserves tissue quality. Journal of Neuroscience, 2: 1129-1149.

9. Moyse $\mathrm{E}$, Rostène $\mathrm{W}$, Vial M, Leonard K, Mazella $P$, Kitabgi $P$, Vincent JP \& Beaudet A (1987). Distribution of neurotensin-binding sites in rat brain: A light microscopic radioautographic study using monoiodo 125 - Tyr $_{3}$-neurotensin. Neuroscience, 22: 526-536.

10. Epelbaum J, Moyse E, Tannenbaum GS, Kordon C \& Beaudet A (1989). Combined autoradiographic and immunohistochemical evidence for an association of somatostatin-binding sites with growth hormone-releasing factor-containing nerve cell bodies in the rat arcuate nucleus. Journal of Neuroendocrinology, 1: 109115.
11. Moyse E, Beaudet A, Bertherat J \& Epelbaum J (1992). Light microscopic radioautographic localization of somatostatin-binding sites in the brainstem of the rat. Journal of Chemical Neuroanatomy, 5 : 75-84.

12. Beauvilain JC, Moyse E, Dutriez I, Mitchell V, Poulain P \& Mazzuca M (1992). Localization of mu opioid receptors on the membranes of nerve endings and tanycytes in the guinea pig median eminence by electron microscopy. Neuroscience, 49: 925936.

13. Hamel E \& Beaudet A (1984). Electron microscopic autoradiographic localization of opioid receptors in rat neostriatum. $\mathrm{Na}$ ture, 31: 155-157.

14. Dana C, Vial M, Leonard K, Beauregard A, Kitabgi $P$, Vincent JP, Rostène $W$ \& Beaudet A (1989). Electron microscopic localization of neurotensin-binding sites in the midbrain tegmentum of the rat. I. Ventral tegmental area and interfascicular nucleus. Journal of Neuroscience, 9: 22472257.

15. Jomary C, Gairin JE \& Beaudet A (1992). Synaptic localization of kappa opiod receptors in guinea pig neostriatum. Proceedings of the National Academy of Sciences, USA, 89: 564-568. 
16. Dournaud $P$, Boudin $H$, Shonbrunn $A$, Tannenbaum G \& Beaudet A (1998). Relationships between somatostatin and the somatostatin sst2A receptor in rat brain: a light, confocal and electron microscopic double labeling study. Journal of Neuroscience (in press).

17. Dournaud $P$, Jazat-Poindessous F, Slama A, Lamour Y \& Epelbaum J (1996). Correlations between water maze performance and cortical somatostatin mRNA and highaffinity-binding sites during aging in rats. European Journal of Neuroscience, 8: 476-485.

18. Dournaud $P, G u Y Z$, Shonbrunn A, Mazella J, Tannenbaum GS \& Beaudet A (1996). Localization of the somatostatin receptor sst2a in rat brain using a specific antipeptide antibody. Journal of Neuroscience, 16: 4468-4478.

19. Nouel D, Gaudriault G, Houle M, Reisine $T$, Vincent JP, Mazella J \& Beaudet A (1997). Differential internalization of somatostatin in COS-7 cells transfected with sst1 and sst2 receptor subtypes: a confocal microscopic study using novel fluorescent somatostatin derivatives. Endocrinology, 138: 296-306.

20. Hukovic N, Panetta R, Kumar U \& Patel YC (1996). Agonist-dependent regulation of cloned human somatostatin receptor types 1-5 (hSSTR1-5): subtype selective internalization or upregulation. Endocrinology, 137: 4046-4049.

21. Roth A, Kreienkamp HJ, Nehring RB, Roosterman D, Meyerhof W \& Richter $D$ (1997). Endocytosis of the rat somatostatin receptors: subtype discrimination, ligand specificity, and delineation of carboxy-terminal positive and negative sequence motifs. DNA Cell Biology, 16: 111119.

22. Nicot A, Bérod A \& Rostène W (1994). Neurotensin receptor expression in the rat forebrain and midbrain: A combined analysis by in situ hybridization and receptor autoradiography. Journal of Comparative Neurology, 341: 407-419.

23. Boudin $H$, Pélaprat $D$, Rostène $W$ \& Beaudet A (1996). Cellular distribution of neurotensin receptors in rat brain: immunohistochemical study using an antipeptide antibody against the cloned high affinity receptor. Journal of Comparative Neurology, 373: 76-89.
24. Kitabgi $P$, Rostène $W$, Dussaillant $M$, Schotte A, Laduron PM \& Vincent JP (1987). Two populations of neurotensinbinding sites in murine brain: discrimination by the antihistamine levocabastine reveals markedly different radioautographic distribution. European Journal of Pharmacology, 140: 285-293.

25. Pinnock RD (1985). Neurotensin depolarizes substantia nigra dopamine neurones. Brain Research, 338: 151-154.

26. Shi WX \& Bunney BS (1992). Actions of neurotensin: a review of the electrophysiological studies. Annals of the New York Academy of Sciences, 668: 129-145.

27. Jiang ZG, Pessia M \& North RA (1994). Neurotensin excitation of rat ventral tegmental neurons. Journal of Physiology, 474: 119-129.

28. Palacios JM \& Kuhar MJ (1981). Neurotensin receptors are located on dopaminergic-containing neurons in rat midbrain. Nature, 294: 587-589.

29. Quirion R, Chiueh CC, Everist HD \& Pert A (1985). Comparative localization of neurotensin receptors on nigrostriatal and mesolimbic dopaminergic terminals. Brain Research, 327: 385-389.

30. Szigethy E \& Beaudet A (1989). Correspondence between high affinity ${ }^{125}$-neurotensin-binding sites and dopaminergic neurons in the rat substantia nigra and ventral tegmental area: a combined radioautographic and immunohistochemical light microscopic study. Journal of Comparative Neurology, 279: 128-137.

31. Boudin H, Gruaz-Guyon A, Faure MP, Forgez $P$, Lhiaubet $A M$, Dennis $M$, Beaudet $A$, Rostène $W$ \& Pélaprat $D$ (1995). Immunological recognition of different forms of the neurotensin receptor in transfected cells and rat brain. Biochemical Journal, 305: 277-283.

32. François-Bellan AM, Bosler O, Tonon MC, Tong WL \& Beaudet A (1992). Association of neurotensin receptors with VIPcontaining neurons and serotonin-containing axons in the suprachiasmatic nucleus of the rat. Synapse, 10: 282-290.

33. Beaudet A (1993). Autoradiographic localization of receptors at the electron microscopic level. In: Wharton J \& Polak JM (Editors), Receptor Autoradiography. Principles and Practices. Oxford University Press, Oxford, 135-158.
34. Woulfe J \& Beaudet A (1989). Neurotensin terminals form synapses primarily with neurons lacking detectable tyrosine hydroxylase immunoreactivity in the rat substantia nigra and ventral tegmental area. Journal of Comparative Neurology, 321: 163-176.

35. Szigethy E, Leonard K \& Beaudet A (1990). Ultrastructural localization of [ ${ }^{125}$ I] neurotensin-binding sites to cholinergic neurons of the rat nucleus basalis magnocellularis. Neuroscience, 36: 377-391.

36. Faure MP, Nouel D \& Beaudet A (1995). Axonal and dendritic transport of internalized neurotensin in rat mesostriatal dopaminergic neurons. Neuroscience, 68: 519529.

37. Nouel D, Faure MP, St. Pierre JA, Alonso R, Quirion R \& Beaudet A (1997). Differential-binding profile and internalization process of neurotensin via neuronal and glial receptors. Journal of Neuroscience, 17: 1795-1803.

38. Faure MP, Alonso A, Nouel D, Gaudriault G, Dennis M, Vincent JP \& Beaudet A (1995). Somatodendritic internalization and perinuclear targeting of neurotensin in mammalian brain. Journal of Neuroscience, 15: 4140-4147.

39. Mantyh PW, Allen CJ, Ghilardi JR, Rogers SD, Mantyh CR, Liu H, Basbaum Al, Vigna SR \& Maggio JE (1995). Rapid endocytosis of a $G$ protein-coupled receptor: substance P-evoked internalization of its receptor in the rat striatum in vivo. Proceedings of the National Academy of Sciences, USA, 92: 2622-2626.

40. Liu H, Mantyh PW \& Basbaum Al (1997). NMDA-receptor regulation of substance $P$ release from primary afferent nociceptors. Nature, 368: 721-724.

41. Beaudet A, Mazella J, Nouel D, Chabry J, Castel MN, Laduron P, Kitabgi P \& Faure MP (1994). Internalization and intracellular mobilization of neurotensin in neuronal cells. Biochemical Pharmacology, 47: 4352.

42. Yu SS, Lefkowitz RJ \& Hausdorff WP (1993). B-adrenergic receptor sequestration. A potential mechanism of receptor resensitization. Journal of Biological Chemistry, 268: 337-341.

43. Laduron PM (1994). From receptor internalization to nuclear translocation. Biochemical Pharmacology, 47: 3-13. 